Subsequent follow-up (during the first year of life) showed that in children of the main group were less frequently detected functional disorders of the gastrointestinal tract $(15.8 \%$ vs $36.5 \%, \mathrm{P}=0.034)$ and allergic diseases $(1.2 \%$ vs $5.8 \%, \mathrm{P}=0.056)$.

In newborns whose mothers received a probiotic during the 6 weeks before delivery, after birth levels of both markers of intestinal inflammation (fecal eosinophil-derived protein and fecal calprotectin) were significantly lower than in comparison group (children whose mothers not used probiotics).

In addition, in children of the main group in the first year of life were less than half detected such conditions as functional disorders of the gastrointestinal tract and manifestations of food allergies.

\section{EARLY NEONATAL OUTCOME OF NEWBORNS WITH MOTHERS HYPOTHYREOSIS IN PREGNANCY}

Diana Milas*, Gordana Lukić, Tihana Nað, Andrea Prutki. OŽB VUKOVAR, Medicinski fakultet Osijek

\subsection{6/archdischild-2021-europaediatrics. 112}

Newborns of mothers with hypothyroidism (latent or manifest) in pregnancy were investigated during two one-year periods. The aim was to point out particularities in mother's anamnesis, pregnancy and labour, as well as the clinical characteristics of neonates (Apgar score, gestational age, birth weight, mode of delivery) and to compare the differences in two periods.

Subjects The research was conducted on newborns of mothers with hypothyroidism in pregnancy in the Clinical Hospital Centre Osijek in 2015 and 2018. The control group consisted of newborns first born afterwards.

The data were presented in tables, in absolute and relative frequencies.

Chi-square test was used to demonstrate the statistical significance, resulting in significance level of $\mathrm{p}<0.05$. It was retrospective case control study.

Mothers with hypothyroidism in pregnancy had more acute complications in pregnancy (infections, hypertension, preeclampsia, gestational diabetes) and delivery, and more complications in reproductive anamneses. Urgent Caesarean section was much more common for their newborns. C-reactive protein among them was often higher than $5 \mathrm{mg} / \mathrm{l}$. They gave birth prematurely more often, while infections, cyanosis, hypoand hypertonus, and jaundice were also more common. Complications of prematurity and the need for oxygenation occurred much more often than in the control group. They were also hospitalized longer. Comparing the two one-year periods, we found less complications during pregnancy and delivery in the year 2018; the frequency of mothers with bad reproductive anamnesis was three times lower, as was the number of urgent Caesarean sections. The number of newborns born prematurely was two times smaller. In 2018, neonatal outcome included three times less common onset of infection, cyanosis, hypo- and hypertonus, and less common preterm labour. The need for oxygenation was five times, and for prolonged hospitalisation nine times less common.

Conclusion Better perinatal care and screening of mothers with hypothyroidism improves neonatal outcome as well as long-life consequences in newborns and lowers the complication rates for mothers during pregnancy and delivery.

\section{UMBILICAL CORD BLOOD CYTOKINES TNF $\alpha$ AND IFN $\gamma$ LEVELS INCREASED IN CHILDREN BORN TO MOTHERS WHO ARE OBESE}

${ }^{1}$ VP Novikova*, ${ }^{1} Y u$ V Petrenko, 'DO Ivanov, ${ }^{1}$ NE Prokopyeva, ${ }^{1} O P$ Gurina, ${ }^{1}$ AE Blinov, ${ }^{1}$ ON Varlamova, ${ }^{2}$ TV Kosenkova, ${ }^{2}$ EA Boytsova. 'Saint-Petersburg State Pediatric Medical University; ${ }^{2}$ Federal State Budgetary Institution «V.A. Almazov National Medical Research Center» of the Ministry of Health of the Russian Federation, Saint-Petersburg

\subsection{6/archdischild-2021-europaediatrics. 113}

Introduction Maternal obesity is considered one of the several key factors that affect development of the immune system of newborns. Experimental and clinical data indicate an increased risk of developing autoimmune, allergic diseases and obesity in the offspring of obese mothers. The main mechanisms of the relationship between mother's body weight and the immune system of a newborn person remain poorly understood.

Objectives Aim of this study was to analyze the cytokine status of umbilical cord blood of children born to mothers with obesity.

Methods Umbilical cord blood samples were taken from 65 children born to thin $(\mathrm{n}=24)$, with overweight $(\mathrm{n}=9)$ and obese mothers $(\mathrm{n}=32$ ). The levels of TNF $\alpha$, TGF $\beta 1$, IL 18, IL 13, IL10 and IFN $\gamma$ were quantified by IFA. Statistical processing of data was performed on a personal computer using licensed computer software 'Microsoft Excel 2016' and 'STATISTICA 12'. The Student t-test value was determined while analyzing the distribution of quantitative data. The criterion of statistical significance level was $\mathrm{p}<0.05$.

Results Compared to children born to thin mothers, children born to obese mothers had higher levels of umbilical cord blood plasma TNF $\alpha(12,75 \pm 10,80 \mathrm{pg} / \mathrm{ml}$ and 4,94 $\pm 3,55 \mathrm{pg} /$ $\mathrm{ml} ; \mathrm{P} 1,3=0,005408)$ and IFN $\gamma(798,90 \pm 565,96 \mathrm{pg} / \mathrm{ml}$ and 311,05 $\pm 249,08 \mathrm{pg} / \mathrm{ml} ; \mathrm{P} 1,3=0,014947$ ).

Conclusion These results confirm the hypothesis that maternal obesity affects programming of the immune system of newborns providing a potential connection with an increase in the incidence of chronic inflammatory diseases and obesity in offspring.

\section{HYPOTHERMIA IS PREVENTABLE}

L Collins*, J Wood, A Faire, G Kakade, S Barrett, F Patel, Deepa Panjwani, S Rao. East Suffolk and North Essex NHS Trust Colchester Hospital

\subsection{6/archdischild-2021-europaediatrics. 114}

Background Temperature regulation is an important part of new-born care.

This is especially true of pre-term infant and those with the low-birth weight, which represent a significant proportion of the population in the neonatal unit.

Aim The audit was performed to assess the quality of care in relation of hypothermia. The audit was aimed at observing babies admitted to neonatal unit Leicester Royal Infirmary and Leicester General during the months of June -July (period 1) and November - December (period 2), with a body temperature below the 36.5. The second objective was to look at the documentation of the admission temperature

Methods The data was collected retrospectively. Babies were identify using the online record system. Data was also collected on gestational age, birth weight, reason for admission 
and duration of stay. The data was recorded and analysed using Microsoft Excel and kept anonymous. After the first review, we applied the teaching sessions for the labour staff/ midwives and also introduced the flyer/poster was displayed in theatres, postnatal wards, labour wards. Email sent to all staff at LGH and LRI Maternity units Results. There were 119 admissions between period 1 and 124 admissions between period 2. Temperature recordings within 30 minutes of admission to the Neonatal Unit was measured and documented for babies in first period as $99 \%$ and $100 \%$ in second period. $100 \%$ achievement of admission target temperatures between 36.5 - $37.50 \mathrm{C}$ were recorded as $81 \%$ and $86 \%$ for respective periods. There were 24 and 21 patients who had temperatures outside the limit. The majority of patients had temperature $>36.5$ as they have been admitted for sepsis treatment. Babies with hypothermia were $>33$ and $<37$ weeks gestational in $42 \%$ and $44 \%$ in reviews. $50 \%$ of babies were above $2.5 \mathrm{~kg}$ in period 2 . For both periods, babies admitted with a temperature lower than 36.5 were treated for sepsis and they were admitted from labour ward and theatre.

Conclusion An excellent level of documentation compliance was observed.

With minimum intervention, normothermic admissions improved to $5 \%$. There still remains room for improvement in areas to prevent hypothermia. The particular at-risk age group appears to be between 33-37 weeks and weight above $2.5 \mathrm{~kg}$.

\section{CASE REPORT: CONGENITAL CHYLOTHORAX PRESENTING WITH SEVERE HYDROPS IN A LATE PRETERM NEONATE SUCCESSFULLY TREATED WITH OCTREOTIDE}

Krešimir Šantić*, Darjan Kardum, Mirna Sipl, Dalibor Divković, Krešimir Ivaković, Andrijana Šantić. University Hospital Centre Osijek

\subsection{6/archdischild-2021-europaediatrics. 115}

Fetal hydrops is an accumulation of fluid in more than one extravascular space. Congenital chylothorax is a rare cause of non-immune fetal hydrops, and the prognosis is generally very poor. There is no consensus on the optional treatment of congenital chylothorax. Conservative treatments (low-fat high-protein diets with medium-chain triglycerides, total parenteral nutrition) and surgical interventions are performed. There is mounting evidence for the use of octreotide (a somatostatin analog) in cases nonresponsive to conservative treatment, but no specific recommendation as to the dose and the length of therapy exist so far.

We report a male, late preterm newborn, with a birth weight of 3600 grams, born to a Caucasian 28-year-old secundigravida via cesarean section because of poor fetal biometric markers at 35 3/7 week gestation. Neonate was born with congenital chylothorax and severe non-immune hydrops. After the therapeutic failure of enteral low long-chain triglyceride formula and full parenteral nutrition in reducing chyle leak, the patient was treated with octreotide and shown rapid improvement. We conclude that octreotide treatment is a plausible therapeutic option before surgical treatment in patients with congenital chylothorax.

\section{6} A GRAVE AFFAIR-AN UNUSUAL CASE OF CONGENITAL THYROTOXICOSIS IN A PRETERM BABY CAUSED BY TRANSPLACENTAL PASSAGE OF MATERNAL THYROID STIMULATING HORMONE ANTIBODIES DURING PREGNANCY

S Parker*, S Rao, RMJ Anderson, WL Lee. Colchester Hospital

\subsection{6/archdischild-2021-europaediatrics. 116}

Introduction Congenital hyperthyroidism is a rare disease that can affect infants born to mothers with Graves disease. Thyroid stimulating hormone receptor antibodies (TRAb) cross the placenta and can cause foetal and neonatal thyrotoxicosis.

This can have implications on foetal growth and may cause intra uterine growth restriction as well as cardiovascular complications such as foetal tachycardia. Postnatally signs of hyperthyroidism may include tachycardia, hypertension, irritability and poor weight gain. This case illustrates how high maternal TRAb led to foetal thyroid stimulation and thus foetal and neonatal thyrotoxicosis. It also demonstrates the difficulties encountered in managing the affected baby after birth.

Report Baby was born at $34+3$ weeks. Maternal history of Graves disease for which mother underwent a thyroidectomy 5 years previously. She was on thyroxine replacement. Mother was euthyroid during pregnancy. Foetal tachycardia was noted from 20 weeks gestation and the thyroid gland showed increased vascularity on antenatal scans. Baby also had a VSD and mild ventriculomegaly.

During this time maternal TRAb was measured at $>30$ (upper normal range >0.4). Carbimazole was started at 26 weeks, resulting in improvement of foetal tachycardia.

Baby was born in good condition weighing $1540 \mathrm{~g} \quad(<2$ nd centile). After birth baby was constantly jittery, irritable and tachycardic. Innitial TRAb was raised at 27.5 and TSH was $<0.02$. After liaising with a tertiary unit paediatric endocrine team, the baby was started on propranolol and then carbimazole. Symptoms of thyrotoxicosis improved after starting treatment and after 2 weeks baby was discharged from our neonatal unit. Thyroid function as well as TRAb were monitored closely and propranolol and then carbimazole were discontinued by 1 month. Baby has since needed thyroxine replacement therapy, and continues to be closely monitored and managed by the local paediatric team in close cosultation with the tertiary paediatric endocrine unit.

Conclusion This is a rare case of fetal and neonatal thyrotoxicosis. It demonstrates that despite maternal treatment with thyroidectomy and the mother being euthyroid during pregnancy, transplacental passage of TRAb can cause thyrotoxicosis in the foetus and later on the neonate. Although such cases are rare they have a relatively high mortality and morbidity. It shows the significant implications on the baby's growth and cardiovascular compromise that may occur with thyrotoxicosis in the newborn. In addition it highlights the complex management of this group.

\section{INCIDENCE OF NEONATAL SEPSIS TREATED IN PICU, UNIVERSITY HOSPITAL OF SPLIT, CROATIA}

Branka Polić*, Ivana Čović, Joško Markić, Tanja Kovačević, Tatjana Ćatipović Ardalić, Julije Meštrović. Department of Paediatrics, University Hospital of Split, Split, Croatia

10.1136/archdischild-2021-europaediatrics. 117 